\title{
KAJIAN INTERAKSI OBAT PADA PENGOBATAN DIABETES MELITUS (DM) DENGAN HIPERTENSI DI INSTALASI RAWAT JALAN RSUD UNDATA PERIODE MARET-JUNI TAHUN 2014
}

\section{STUDY OF DRUG INTERACTION IN TREATMENT OF DIABETES MELITUS WITH HYPERTENSION IN OUTPATIENT INSTALLATION IN RSUD UNDATA PALU PERIOD MARCH-JUNE 2014}

\author{
Ida Nurlaelah $^{1 *}$, Alwiyah Mukaddas ${ }^{1}$, Ingrid Faustine ${ }^{1}$ \\ ${ }^{1}$ Jurusan Farmasi, Fakultas MIPA, Universitas Tadulako, Palu, Indonesia
}

Received 25 Januari 2015, Accepted 30 Februari 2015

\begin{abstract}
ABSTRAK
Penelitian ini bertujuan untuk mengetahui profil peresepan pasien DM dengan hipertensi meliputi jumlah obat yang diresepkan, bentuk sediaan, golongan dan jenis obat serta insidensi terjadinya interaksi obat secara teoritik, berdasarkan mekanisme interaksi obat di instalasi rawat jalan RSUD Undata Palu tahun 2014. Penelitian ini merupakan penelitian non-ekperimental dengan rancangan penelitian deskriptif.Pengambilan data pasien dilakukan secara prospektif selama periode Maret-Juni 2014. Subyek yang memenuhi kriteria inklusi yaitu pasien dewasa usia 18-60 tahun serta terdiagnosa DM dengan hipertensi diwawancara untuk mendapat data primer sedangkan data skunder berupa rekam medik dan resep.Diperoleh 61 sampel penelitian. Berdasarkan profil peresepan bentuk sediaan yang paling sering diberikan pada pasien DM dengan hipertensi adalah tablet $(94,5 \%)$. Golongan obat diabetes yang paling banyak digunakan adalah sulfonilurea $(21,1 \%)$ dan golongan obat hipertensi Beta bloker $(12,2 \%)$. Jenis obat diabetes yang paling banyak digunakan adalah Glimepirid $(14,9 \%)$ dan hipertensi adalah Bisoprolol (9,6\%). Persentase hasil interaksi obat secara teoritik adalah 85,2\% (52 pasien), jenis interaksi obat yang paling banyak terjadi adalah interaksi farmakodinamik 72,7\%. Pasien diabetes melitus dengan hipertensi di instalasi rawat jalan RSUD Undata Palu tahun 2014 sebagian besar mengalami interaksi obat.
\end{abstract}

Kata Kunci: Diabetes melitus dengan hipertensi, Interaksi obat, Farmakodinamik

\section{ABSTRACT}

This study aims to determine the prescription profile of DM patients with hypertension include the number of drugs prescribed, dosage forms, classes and types of drugs and the incidence of drug interactions theoretically, based on the mechanism drug interactions in outpatient installations of RSUD Undata Palu 2014. This design research is a non-experimental study with descriptive. Retrieval of patient data performed prospectively during the period from March to June2014. Subjects who fill the inclusion criteria is adult patients that attainage of 18-60 years and diagnosed diabetes mellitus with hypertension are interview to obtain primary data while the secondary data such as medical records and prescriptions. Retrieved 61sample. Based on dosage forms prescribe profile that most often given to the DM patients with hypertension was tablets (94.5\%). Class of diabetes drugs most widely used is a sulfonylurea $(21.1 \%)$ and hypertension drug classes beta blocker $(12.2 \%)$. types of diabetic drugs most widely used was glimepiride $(14.2 \%)$ and hypertension was bisoprolol $(9.2 \%)$. The percentage result of drug interactions theoretically was $85.2 \%$ (52 patients), drug interactions type that the most occurred was pharmacodynamic 
interactions 72.7\%. Diabetes melitus Patients with hypertension in outpatient installations of RSUD Undata Palu 2014 were most potentially subjected to drug interactions.

Keywords : Diabetes mellitus with hypertension, Pharmacodynamic, Drug interaction

*) Coresponding author : Ida nurlaelah, idalaela886@yahoo.co.id (ph: +62-821-8801-6560)

\section{PENDAHULUAN}

Diabetes Melitus (DM) merupakan kelompok penyakit metabolik yang ditandai dengan hiperglikemia. DM) terdiri dari dua tipe yaitu tipe pertama DM yang disebabkan keturunan dan tipe kedua disebabkan life style atau gaya hidup. Secara umum, hampir $80 \%$ prevalensi DM adalah DM tipe 2(Endah, 2007)).

World Health Organization (WHO) melaporkan bahwa 60\% kematian semua umur di dunia adalah penyakit tidak menular (PTM).Diabetes mellitus menduduki peringkat keenam sebagai penyebab kematian. Sekitar 1,3 juta orang meninggal akibat diabetes dan 4 persen meninggal sebelum usia 70 tahun (Anonim, 2013).Hasil Riset kesehatan Dasar (Riskesdas) tahun 2013Prevalensi diabetes yang terdiagnosis dokter atau gejala, tertinggi terdapat di Sulawesi Tengah (3,7\%)(Anonim, 2006).Menurut data Dinas Kesehatan Provinsi Sulawesi Tengah pada tahun 2010 penyakit diabetes melitus di Sulawesi Tengah menduduki peringkat kelima terbanyak rawat jalan di RSU Pemerintah Sulawesi Tengah dengan jumlah kasus sebanyak 863 presentase 8,31\% (Anonim, 2011).

Selain DM, pasien biasanya juga mengalami penyakit penyerta sehingga membutuhkan berbagai macam obat dalam terapinya. Terapi dengan beberapa obat sekaligus (polifarmasi) dapat mengakibatkan terjadinya interaksi obat. Interaksi obat terjadi jika efek salah satu obat berubah karena keadaan obat lain, makanan, minuman, atau berbagai agen kimia lingkungan (Stockley, 2010).

Hipertensi lebih sering ditemukan 1,5 sampai 3 kali lebih banyak pada penderita diabetes mellitus dibandingkan tanpa diabetes (Anonim, 2006).Penderita diabetes dengan hipertensi mempunyai resiko kematian kardiovaskular lebih besar dibandingkan penderita diabetes tanpa hipertensi. Penderita diabetes dengan hipertensi juga meningkatkan resiko terjadinya retinopati dan nefropati (Anonim, 2006).

Menurut laporan Institute of Medicine, angka kejadian (incidence) dari interaksi obat dalam klinik cukup besar.Berdasarkan data, diketahui bahwa 44.000 - 98.000 kematian terjadi setiap tahunnya akibatberbagai kesalahan dalam klinis, dan sekitar 7.000 kematian terjadi karena efek sampingdari pengobatan yang dilakukan (termasuk akibat dari interaksi obat) (Krisantini, 2011).

Pada tahun 2013menurut data di RSUD Undata DM menempati peringkat 5 besar penyakit yang diderita pasien rawat jalan di RSUD Undata Palu, dengan jumlah 326 pasien.

Ruang lingkup dari penelitian ini adalah pasien yang mendapat pengobatan DM dengan hipertensi di Instalasi Rawat 
Jalan RSUD Undata Palu periode MaretJuni 2014.

Berdasarkan latar belakang di atas perlu dilakukan penelitian tentang kajian interaksi obat pada pengobatan diabetes melitus dengan hipertensi di instalasi rawat jalan RSUD Undata Palu.

\section{METODE PENELITIAN}

\section{Desain Penelitian}

Penelitian yang akan digunakan dalam penelitian ini merupakan penelitian non eksperimental observasional dimana data dikumpulkan secara prospektif dan hasil penelitian disajikan secara deskriptif. Sampel yang diambil adalah pasien diabetes dengan hipertensi yang menjalani rawat jalan di RSUD Undata Palu periode MaretJuni 2014. Data primer meliputi umur, lama diabetes, lama hipertensi, keluhan pasien saat pemakaian obat bersamaan dan data sekunder berupa data rekam medik dan resep.

Teknik pengambilan sampel adalah total sampling yaitu dengan mengumpulkan semua pasien dengan data yang memenuhi kriteria inklusi dan eksklusi.

Kriteria Inklusi

1.) pasien terdiagnosa diabetes melitus dengan hipertensi

2.) Pasien dewasa usia 18-60 tahun.

3.) Bersedia ikut penelitian

Kriteria Eksklusi

1.) Pasien yang terdiagnosadiabetes melitus dengan hipertensi tapi tidak menerima terapi obat.
2.) Pasien menerima terapi selain obat diabetes melitus atau hipertensi yaitu obat untuk penyakit kronik dan dapat menyebabkan interaksi yang lain.

Data yang didapat yaitu data primer dan sekunder kemudian dianalisis persentase profil peresepen pasien DM dengan hipertensi dan terjadinya interaksi obat baikberdasarkan jumlah pasien maupunjumlah kejadian yang terjadi denganbuku standar Drug Interaction Factdari Tatro tahun 2001 dan jikaditemukan keterangan yang belumlengkap maka diambil buku standarDrug Interaction dari Stockley tahun 2010, Adverse Drug Interactiondari Karalliedde tahun 2010, Drug Interaction dari Hansten tahun 2001 dan Handbook of PharmacologydariLacy tahun 2002.

\section{HASIL DAN PEMBAHASAN} Hasil

Pasien yang terdiagnosa DM dengan hipertensi yang masuk dalam kriteria inklusi dan eksklusi sebanyak 61 pasien. Hasil penelitian menunjukkanbahwa pasien terdiri 25 pasien laki-laki(41,0\%) dan 36 pasien perempuan $(59,0 \%)$. Berdasarkan distribusi umurterdapat 14 pasien $(23,0 \%)$ berusia 18-40tahun dan 47 pasien (77\%) berusia41-60 tahun.

Berdasarkan hasil wawancara kepada pasien dan data rekam medik serta resep yang diberikan didapatkan data sebagai berikut yang disajikan dalam Tabel di bawah ini. 
Tabel 1. Jumlah obat yang diresepkan

\begin{tabular}{ccc}
\hline Jumlah Obat & Jumlah & $\begin{array}{c}\text { Persentase } \\
(\%)\end{array}$ \\
\hline $1-3$ obat & 22 & 36.1 \\
$4-6$ obat & 39 & 63.9 \\
\hline Total & 61 & 100
\end{tabular}

Tabel 2. Bentuk sediaan

\begin{tabular}{ccc}
\hline $\begin{array}{c}\text { Bentuk } \\
\text { sediaan }\end{array}$ & Jumlah & Persentase (\%) \\
\hline Tablet & 215 & 94.5 \\
Kapsul & 7 & 4.1 \\
Tts mata & 2 & 0.8 \\
Suspensi & 4 & 0.8 \\
\hline Total & 228 & 100 \\
\hline
\end{tabular}

Tabel 3. Golongan obat

\begin{tabular}{cccc}
\hline Obat & Golongan Obat & Jumlah & $\mathbf{( \% )}$ \\
\hline Diabetes & Sulfonilurea & 48 & 35,5 \\
melitus & Biguanida & 33 & \\
Hipertensi & ACE Inhibitor & 22 & \\
& Antagonis kalsium & 24 & \\
& Beta blocker & 28 & 40,3 \\
& Loop diuretik & 5 & \\
& Diuretik hemat kalium & 3 & \\
Obat lain & ARBs & 10 & \\
& Antasida & 2 & \\
& Vitamin & 21 & \\
& Antivertigo & 1 & 24,2 \\
& Analgesik & 2 & \\
& Antagonis reseptor H2 & 1 & \\
& Mukolitik & 2 & \\
& PPP & 7 & \\
& NSAID & 18 & \\
\hline
\end{tabular}

Keterangan; NSAID (Non Steroid Anti Inflamsi Drug) ARBs(Angiotensin Reseptor Blocker) PPP (Penghampat Pompa Proton)

Tabel 4. Jenis obat yang diresepkan

\begin{tabular}{cccc}
\hline Golongan Obat & Jenis Obat & $\begin{array}{c}\text { Jumlah } \\
\text { Obat }\end{array}$ & (\%) \\
\hline Sufonilurea & Glimepirid & 34 & 14,9 \\
& Glikazida & 14 & 6,1 \\
Biguanida & Metformin & 33 & 14,4 \\
ACE Inhibitor & Lisonopril & 14 & 6,1 \\
& Ramipril & 4 & 1,7 \\
& Catopril & 4 & 1,7 \\
\hline
\end{tabular}

\begin{tabular}{cccc}
\hline Beta Blocker & Bisoprolol & 22 & 9.6 \\
& Propanolol & 5 & 2,1 \\
& karvediolol & 1 & 0,4 \\
ARBs & Candesartan & 6 & 2.6 \\
& Valsartan & 4 & 1.7 \\
Antagonis & Amlodipin & 22 & 9.6 \\
kalsium & Nifedipin & 2 & 0,8 \\
Diuretik Hemat & Spiranolacton & 3 & 1,3 \\
kalium & & & \\
Loop diuretik & Furosemid & 6 & 2,6 \\
Analgesik non & Paracetamol & 2 & 0,8 \\
opioid & & & \\
NSAID & Meloxicam & 18 & 7.8 \\
Antasida & Antasida & 2 & 0,8 \\
Antagonis & Ranitidin & 1 & 0,4 \\
Reseptor H2 & & & \\
Antivertigo & Betahistin & 1 & 0,4 \\
PPP & Lansoprazol & 7 & 3,0 \\
Mukolitik & GG & 2 & 0.8 \\
Vitamin & Vitamin B1, & 21 & 9,2 \\
& B2, B6, B12, C & & \\
\hline Jumlah & & 228 & 100 \\
\hline
\end{tabular}

Keterangan; NSAID (Non Steroid Anti Inflamsi Drug) ARBs(Angiotensin Reseptor Blocker) PPP (Penghampat Pompa Proton)

Tabel 5. Insidensi terjadinya interaksi obat

\begin{tabular}{lcc}
\hline \multicolumn{1}{c}{ Keterangan } & Jumlah Pasien & $\mathbf{( \% )}$ \\
\hline Terjadi interaksi obat & 52 & 85.2 \\
Tidak terjadi interaksi obat & 9 & 14.7 \\
\hline Jumlah & 61 & 100 \\
\hline
\end{tabular}

Tabel 6. Jenis interaksi obat berdasarkan mekanisme interaksi

\begin{tabular}{ccc}
\hline Mekanisme & $\begin{array}{c}\text { Jumlah Jenis } \\
\text { Interaksi }\end{array}$ & $\mathbf{( \% )}$ \\
\hline Farmakodinamik & 8 & 72.7 \\
Farmakokinetik & 2 & 18.2 \\
Unkown & 1 & 9.1 \\
\hline Jumlah & 11 & 100 \\
\hline
\end{tabular}

\section{Pembahasan}

Profil peresepan obat pada pasien diabetes melitus dengan hipertensi di Instalasi Rawat Jalan RSUD Undata Palu Maret-Juni 2014 persentase pasien dengan obat yang tertinggi adalah 4-6 obat $63.9 \%$ (39 pasien). Bentuk sediaan obat yang paling sering digunakan adalah tablet 
94,5\%. Golongan obat diabetes yang paling banyak digunakan adalah sulfonilurea $21,05 \%$ (48 obat) dan golongan obat hipertensi beta bloker 12,28\% (28 obat). Jenis obat diabetes yang paling banyak digunakan adalah glimepirid (14,9\%) dan hipertensi adalah bisoprolol (9,6\%).

Persentase pasien yang kemungkinan mengalami interaksi obat adalah $85.2 \%$ (52
pasien).Identifikasi interaksi obat dapat dilihat dalam tabel 7.Interaksiobat adalah situasi di mana suatu zat mempengaruhi aktivitas obat lain, yaitu meningkatkan atau menurunkan efeknya, atau menghasilkan efek baru yang tidak diinginkan atau direncanakan.

Tabel 7. Identifikasi interaksi obat

\begin{tabular}{|c|c|c|c|c|}
\hline Mekanisme & Obat A & Obat B & Jumlah & Efek \\
\hline \multirow[t]{19}{*}{ Farmakodinamik } & Glimepirid & Bisoprolol & 7 & \multirow{2}{*}{$\begin{array}{l}\text { Dapat meningkatkan resiko terjadinya } \\
\text { hipoglikemia }\end{array}$} \\
\hline & & Propanolol & 1 & \\
\hline & Glimepirid & Catopril & 3 & Peningkatan sementarasensitivitas \\
\hline & & Lisinopril & 5 & insulinolehACE inhibitor \\
\hline & & Ramipril & 1 & \\
\hline & Glimepirid & Amlodipin & 7 & \multirow{2}{*}{$\begin{array}{c}\text { Antagonis kalsium menghambat kerja } \\
\text { sulfonilurea sehingga berkurangnya } \\
\text { untuk memberikan efek }\end{array}$} \\
\hline & & Nifedipin & 4 & \\
\hline & Glimepirid & Furosemid & 3 & $\begin{array}{l}\text { Furosemiddapat menurunkan toleransi } \\
\text { glukosa, mengakibatkan hiperglikemia } \\
\text { walaupun telah diberikan glimepirid }\end{array}$ \\
\hline & Gliklazida & Bisoprolol & 2 & \multirow{3}{*}{$\begin{array}{c}\text { Dapat meningkatkan resiko terjadinya } \\
\text { hipoglikemia }\end{array}$} \\
\hline & & Propanolol & 2 & \\
\hline & & Karvedilol & 1 & \\
\hline & Gliklazida & Catopril & 6 & \multirow{3}{*}{$\begin{array}{l}\text { Peningkatan sementarasensitivitas } \\
\text { insulinolehACEinhibitor. }\end{array}$} \\
\hline & & Lisinopril & 2 & \\
\hline & & Ramipril & 1 & \\
\hline & Gliklazida & Nifedipin & 3 & \multirow{2}{*}{$\begin{array}{c}\text { Antagonis kalsium menghambat kerja } \\
\text { sulfonilurea berkurangnya untuk } \\
\text { memberikan efek }\end{array}$} \\
\hline & & Nifedipin & 2 & \\
\hline & Metformin & Bisoprolol & 7 & \multirow{3}{*}{$\begin{array}{l}\text { Dapat meningkatkan resiko terjadinya } \\
\text { hipoglikemia. }\end{array}$} \\
\hline & & Propanolol & 4 & \\
\hline & & Karvedilol & 2 & \\
\hline \multirow[t]{3}{*}{ Farmakokinetik } & Metformin & Amlodipin & 8 & \multirow{2}{*}{$\begin{array}{l}\text { Amlodipin dapat meningkatkan } \\
\text { absorbsi Metformin }\end{array}$} \\
\hline & & Nifedipin & 6 & \\
\hline & Metformin & Furosemid & 5 & $\begin{array}{l}\text { Furesomid meningkatkan kadar } \\
\text { metformin dalam darah saat } \\
\text { penggunaan bersama sehingga } \\
\text { menyebabkan hipoglikemia. }\end{array}$ \\
\hline \multirow[t]{2}{*}{ Unknown } & Metformin & Catopril & 4 & \multirow{2}{*}{$\begin{array}{c}\text { Dapat meningkatkan resiko } \\
\text { hipoglikemia }\end{array}$} \\
\hline & & Lisinopril & 7 & \\
\hline
\end{tabular}


Persentase jenis interaksi obat dengan mekanisme farmakokinetik adalah 18.2\% (2 jenis), farmakodinamik adalah $72.7 \% \quad(8$ jenis) dan unknown $9.1 \%$ (1 jenis).Interaksi obat berdasarkan mekanisme farmakokinetik adalahInteraksi obat berdasarkan mekanisme farmakokinetik adalah interaksi yang terjadi apabila satu obat mengubah absorpsi, distribusi, metabolisme dan ekskresi obat lain. Salah satu contoh interaksi farmakokinetik adalah interaksi antara obat metformin dan furosemid. Furosemid meningkatkan kadar metformin dalam darah saat penggunaan bersama sehingga menyebabkan hipoglikemia. Furosemid dan metformin diekskresi di tubular ginjal sehingga bersaing disistem transportasi umum tubular yang menyebabkan berpotensi menyebabkan kadar dari metformin meningkat. Sebuah penelitian interaksi obat dengan menggunakan dosis tunggal (Tatro, 2009).

Interaksi farmakodinamik terjadi ditingkat reseptor dan mengakibatkan berubahnya efek salah satu obat, yang bersifat sinergis bila efeknya menguatkan atau antagonis bila efeknya mengurangi. Salah satu contoh interaksi farmakodinamik adalah interaksi antara glimepirid dan ACE

\section{DAFTAR PUSTAKA}

WHO. (2006). Guidelines for The Management of Hypertension in Patients With Diabetes Mellitus. New York.

WHO. (2006). Guidelines for The Prevention Management and Care of Diabetes Melitus. New York. inhibitor. Peningkatan sementara sensitivitas insulin oleh ACE inhibitor (Tatro, 2009). Kaptopril meningkatkan bradikinin, yang menurunkan produksi glukosa oleh hati. Hipoglikemia dilaporkan sebagai efek samping dari Kaptopril. Pemakaian bersama kedua obat ini menyebabkan efek agonis, sehingga dari efek samping katopril dan efek dari gliklazid yaitu merangsang sekresi insulin menyebabkan efek hipoglikemia meningkat.(Karalliedde, 2010).

Interaksi obat yang terjadi berdasarkan mekanisme yang tidak diketahui adalah Metformin-kaptopril. Penggunaan kaptopril bersama metformin kemungkinan dapat meningkatkan efek metformin untuk menurunkan gula darah dengan mekanisme yang belum diketahui dengan pasti. ACE inhibitor mungkin meningkatkan sensitivitas insulin dan pemanfaatan glukosa (Karalidde, 2010).

Dari uraian dia atas dapat disimpulkan bahwa hampir sebagian besar pasien DM dengan hipertensi di instalasi rawat jalan RSUD kemungkinan mengalami interaksi obat dan jenis interaksi yang paling banyak terjadi adalah interaksi farmakodinamik.

Dinas Kesehatan Provinsi Sulawesi Tengah. (2011). Profil Kesehatan Provinsi Sulawesi Tengah Tahun 2010. Palu.

Kementrian Kesehatan Republik Indonesia. (2013). Riset Kesehatan Dasar. Jakarta. 
Endah P., Daroeham, Mutiakum. (2007). Penyakit Diabetes melitus Hasil Riskesdas di Indonesia. Puslitbang Biomedis dan Farmasi. Jakarta.

Hansten, Philip, D. (2001). Drug Interactions, Analisys is and Management.Facts and Comparisons Publishing Group. Washington.

Karaliedde. Lakhsman. (2010). Adverse Drug Interaction : A Handbook for Preciberbers, British Library Cataloguing in Publication Data. London.
Krisantini. M. (2011). Evaluasi Penggunaan Antihipertensi Pada Pasien Diabetes Melitus 2 Dengan Hipertensi di Instalasi Rawat Inap RS Harapan Magelang (Skripsi). Fakultas Farmasi Universitas Sanata Dharma.Yogyakarta.

Stockley, I. H. (2010). Drug interaction $9^{\text {th }}$ ed. Blackwell Sci Publ. London.

Tatro, D. (2009). Drug Interaction Fact: The Authority on Drug Interactions, Fact \& Comparison A Wolters Kluwer Company. Missouri. 